\title{
Use of oral rehydration therapy in the treatment of childhood diarrhoea in Douala, Cameroon
}

\section{NE Essomba ${ }^{1}$, DC Kedy Koum ${ }^{2}$, D Adiogo $^{2}$, MI Ngwe ${ }^{3}$, Y Coppieters ${ }^{4}$}

1. Department of Public Health, University of Douala, Douala, Cameroon 2. Department of Paediatrics, Univeristy of Douala, Douala, Cameroon

3. Department of Pharmacy, University of Douala, Douala, Cameroon

4. School of Public Health, Université Libre de Bruxelles, Brussels, Belgium

\section{Abstract}

\section{Introduction}

The use of oral rehydration solutions in our context remains limited. This study was conducted to analyze the rate of this use in Douala, Cameroon and thereby determine the factors associated with it.

\section{Method}

A cross-sectional survey was administered to parents of children aged five years and younger during a six-month study period. The studied variables focused on the socio-demographic data of the population, data on diarrhoea and its severity, data on oral rehydration salts (ORS), and data related to other interventions for diarrhoea. The chi-square test was used to qualify associations between variables, with the significance level being set at $5 \%$.

\section{Results}

Overall, 672 people agreed to participate in the study. Among them, $418(62.2 \%)$ correctly defined diarrhoea. When their children develop diarrhoea, the majority of the parents $(348,51.8 \%$ ) reported seeking hospital assistance before any intervention, while 225 parents $(33.5 \%)$ preferred the use of ORS first. Four hundred seventy-five parents $(70.7 \%)$ had heard of ORS and among them $313(65.9 \%)$ had actually given ORS to their children as treatment during these children's most recent episodes of diarrhoea. Of the parents who had given their children ORS, $217(69.3 \%)$ knew how to prepare it, and $122(39.0 \%)$ knew how to administer it. One hundred thirty-five parents $(20.1 \%)$ had administered metronidazole to treat their children's diarrhoea. The age of the children, the parents' level of education, and the number of children in the household significantly influenced the use or non-use of ORS (respectively, $\mathrm{p}<0.001, \mathrm{p}=0.003$ and $\mathrm{p}<0.0001)$. Rehydration was correctly identified by 234 parents $(34.8 \%)$ as the purpose of administering ORS.

\section{Conclusion}

The knowledge and the use of ORS in diarrhoea by the study sample was insufficient. The role of ORS was poorly known. Awareness campaigns can be carried out in order to improve the use of this effective intervention for diarrhoea.

\section{Introduction}

Diarrhoea is the frequent (usually defined as three or more times in a day) passage of liquid or soft stool ${ }^{1}$. It is the most common clinical manifestation of gastrointestinal disease and the second leading cause of death in the world among children less than five years old ${ }^{2,3}$. Worldwide, at least one in five children, aged less than five years, dies of diarrhoea (1.5 million deaths) each year. These deaths are mainly the result of dehydration ${ }^{5}$. To fight against dehydration, the World Health Organization (WHO) has, since the 1970s, recommended oral rehydration therapy (ORT) ${ }^{6}$. ORT during bouts of diarrhoea consists of using either a solution prepared from sachets of oral rehydration salts (ORS), or a solution prepared at home with water, sugar and salt, known as the salt-sugar solution (SSS) ${ }^{7}$. These are simple, effective, and inexpensive treatments, which have contributed to a significant decline in mortality among children less than five years of age ${ }^{8}$. ORT use experienced a growth rate of 9\% between 1995 and 2010, compared to $30 \%$ growth between 1980 and $1995^{\circ}$. This slowdown has been explained by ignorance of ORT, its widespread misuse, and by the lack of conviction by medical staff about its effectiveness ${ }^{10}$. In Cameroon, diarrhoea is ranked as the third most deadly disease in children under five years old ${ }^{11}$. A study conducted in 1988, in the Noun department of West Province, Cameroon, on the knowledge and use of ORT by mothers of children aged $12-23$ months revealed that $23.2 \%$ of mothers were aware of ORS but only $15.2 \%$ had used it during their children's diarrhoea episodes. Two-thirds of the mothers expressed knowledge about SSS, but only one-third of them knew how to prepare $i t^{12}$.

Following the epidemiological data collected from Cameroon's latest Demographic and Health Survey and Multiple Indicator Cluster Survey (DHS-MICS 2011), the use of ORT in under-five children with diarrhoea decreased to $22 \%$ in 2011 from $96 \%$ in the year $2000^{7,13}$. These data are reason for concern and raise the issue of lack of public knowledge about ORT.

In this situation, it is pertinent to determine the rate of use of ORS and find factors associated with its use by parents of children under the age of five years, in order to propose ways to increase ORT use in the management of childhood diarrhoea.

\section{Material And Methods \\ Type and place of study}

This was a prospective cross-sectional study, which ran from January to June 2014 in certain hospital facilities in Douala, Camerooun. Douala is a harbour city and the economic capital of Cameroon, which has approximately 2,147,000 inhabitants, with a density of 2,326 inhabitants per $\mathrm{km}^{2}{ }^{14}$.

\section{Study population}

The study population consisted of adult guardians of children aged five years and younger. The parents of children who were admitted to hospital, underwent outpatient consultations, or were encountered at vaccination sites, and who consented to participate were included in the study.

\section{Sample size and sample selection}

According to the Demographic and Health Survey conducted in 2011 in Cameroon, the ORT use rate was $22 \%{ }^{7}$. The minimal size of the sample was calculated using the Lorentz formula, with a correction factor of 1.5. The calculated minimal size was 396 parents. To achieve this, a two-level sampling method was adopted. The city of Douala has five districts: Douala I, II, III, IV, and V. In each district, hospital facilities where there was a high probability of meeting parents of children aged five years or younger were identified; these facilities included those with a paediatrics department or vaccination services. Depending on their technical capacity and size, health facilities in Cameroon are divided into four categories, with the larger, more equipped hospitals belonging to the first category. Douala General Hospital (DGH), being the only first-category facility in Douala, was automatically included as a sampling site. To select five other hospitals, a draw was held, allowing for one hospital to be randomly selected from each district. The six participating hospitals were: Douala General Hospital 
(DGH), Laquintinie Hospital (Douala I), New-Bell District Hospital (Douala II), Logbaba District Hospital (Douala III), Bonassamma District Hospital (Douala IV), and Bonamoussadi Medical Centre (Douala V). At the various admissions areas, outpatient departments, and vaccination sites, eligible parents were consecutively identified and approached, and those who consented were interviewed.

\section{Data collection}

A questionnaire containing the variables of the study was prepared. This questionnaire was subjected to a test on $10 \%$ of the population of the study allowing certain parameters to be adjusted. The validated final questionnaire consisted of 36 questions administered by one of the investigators, who was a final-year medical student at the time of data collection. All participants provided signed informed consent. Interviews were held in discreet and isolated quarters within the hospital premises. Interviews took between ten and fifteen minutes, depending on the linguistic compatibilities between the interviewer and the interviewees. Whenever necessary, nurses were requested to act as interpreters.

ORS use was the dependent variable. Independent variables included socio-demographic data of the parents (age, sex, residence, ethnicity, religion, profession, number of children, and level of education). Data were also collected related to the parents' knowledge regarding diarrhoea, dehydration, and the clinical features related to illness severity-for example, the significance of the presence of liquid stool, duration of diarrhoea, number of stools per day, thirst or inability to drink, vomiting, unconsciousness, restlessness or irritability, sunken eyes, and decreased skin turgor. Data related to knowledge about preparation, administration and storage of ORS and to the role of ORS in the treatment of childhood diarrhoea compared to other treatments were also collected.

\section{Data analysis}

The data were entered and analyzed using EPI Info version 7.0 and Microsoft Excel 2007. Data analysis included calculating and comparing descriptive proportions and percentages. The chi-square test was used to assess associations between variables, with the significance level set at $5 \%$.

\section{Ethical considerations}

The study received the approval of the regional and local health authorities as well as that of the National Ethics Committee. All participants provided informed consent prior to being interviewed.

\section{Results}

\section{Demographic data}

One hundred twelve parents were interviewed in each of the six hospitals, making a total of 672 participants. Among them, $643(95.7 \%)$ were mothers. Parents of children aged one to twelve months were the most represented (250, $37.2 \%)$. It was noted that 392 parents $(58.3 \%)$ had at least two or more children in their homes. Four hundred thirtyfive parents $(64.7 \%)$ had only one child of less than five years old, while $237(35.3 \%)$ had at least two children less than five years of age in their households. Concerning the level of education of these parents, $340(50.6 \%)$ had secondarylevel education. Regarding participant professions, $42.7 \%$ were non-executive employees, $35.1 \%$ were housewives and unemployed, $17.2 \%$ were students, and $4.9 \%$ were executive employees.

\section{Knowledge about diarrhoea}

\section{Knowledge about diarrhoea and severity}

Among the 672 parents, 418 (62.2\%) knew how to define diarrhoea, and $552(82.1 \%)$ perceived it as a serious condition. The majority of the parents $(660,98.2 \%)$ were able to identify at least one danger sign, associated with diarrhoea, that should warrant seeking medical attention. The warning signs raised by the participants are represented in Figure 1.

\section{Experience of parents in the management of diarrhoea}

About half of the parents with a single child had no experience in the management of diarrhoea, whereas the majority of those having more than one child had at least some experience, $(p \leq 0.05)$. Table 1 shows the experience levels of parents in the management of diarrhoea, depending on the number of children under five years of age in the household.

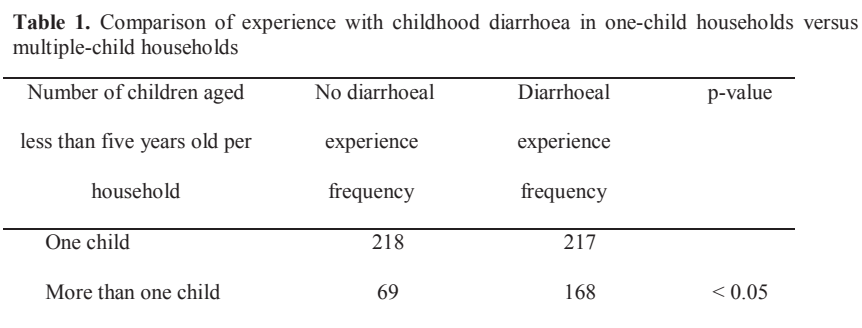

\begin{tabular}{|c|c|c|c|}
\hline & & Frequency & $\%$ \\
\hline Preparation or mode of & 1sachet/1 cup of water & 21 & 4.4 \\
\hline \multirow[t]{5}{*}{ dilution } & $(200 \mathrm{~mL})$ & & \\
\hline & 1sachet $/ 0.5 \mathrm{~L}$ water & 32 & 6.7 \\
\hline & 1sachet $/ 1 \mathrm{~L}$ water & 217 & 45.7 \\
\hline & 1 sachet $/ 1.5 \mathrm{~L}$ water & 100 & 21.1 \\
\hline & No idea & 105 & 22.1 \\
\hline Administration of the & Morning, Afternoon, & 28 & 5.9 \\
\hline \multirow[t]{5}{*}{ ORS } & Evening & & \\
\hline & When (s)he wants to drink & 223 & 46.9 \\
\hline & Suggests regular amount of & 122 & 25.7 \\
\hline & the solution & & \\
\hline & No idea & 102 & 21.5 \\
\hline \multirow[t]{5}{*}{ Storage of the ORS } & At most 24 hours & 317 & 66.7 \\
\hline & At most 2days & 15 & 3.2 \\
\hline & At most 3days & 16 & 3.4 \\
\hline & Until it finishes & 23 & 4.8 \\
\hline & No idea & 104 & 21.9 \\
\hline
\end{tabular}

\section{Parents' first action during a child's bout of diarrhoea}

In the case of a child with diarrhoea, most parents (348, $51.8 \%$ ) reported that they seek hospital attention as a first resort, whereas the other parents prefer to initially manage diarrhoea at home. Concerning interventions for diarrhoea, 225 parents $(33.5 \%)$ favour ORS as the first treatment. Other treatments given are shown in Figure 2. 
Table 3. Relationship between socio-demographic factors and the use of oral rehydration solution (ORS )and salt-sugar solution (SSS)

\begin{tabular}{|c|c|c|c|c|c|c|}
\hline & & & \multicolumn{2}{|c|}{ Use of ORS } & \multicolumn{2}{|c|}{ Use of ORS and SSS } \\
\hline & & Frequency & Frequency & $\%$ & Frequency & $\%$ \\
\hline \multirow[t]{7}{*}{ Age of child } & $0-1$ month & 91 & 28 & 30.8 & 32 & 35.2 \\
\hline & $1-12$ months & 250 & 82 & 32.8 & 98 & 39.2 \\
\hline & $13-23$ months & 73 & 40 & 54.8 & 44 & 60.3 \\
\hline & $24-35$ months & 98 & 58 & 59.2 & 67 & 68.4 \\
\hline & $36-47$ months & 93 & 65 & 69.9 & 68 & 73.1 \\
\hline & $48-59$ months & 67 & 40 & 59.7 & 43 & 64.2 \\
\hline & & & & $(\mathrm{p}<0.05)$ & & $(\mathrm{p}<0.05)$ \\
\hline \multirow{3}{*}{$\begin{array}{r}\text { Number of } \\
\text { children }\end{array}$} & 1 & 435 & 158 & 36.3 & 184 & 42.3 \\
\hline & $>1$ & 237 & 155 & 65.4 & 168 & 70.9 \\
\hline & & & & $(\mathrm{p}<0.05)$ & & $(\mathrm{p}<0.05)$ \\
\hline \multirow{5}{*}{$\begin{array}{r}\text { Level of } \\
\text { education }\end{array}$} & None & 41 & 11 & 26.8 & 12 & 29.3 \\
\hline & Primary & 78 & 34 & 43.6 & 41 & 52.6 \\
\hline & Secondary & 340 & 159 & 46.8 & 177 & 52.1 \\
\hline & University & 213 & 109 & 51.2 & 122 & 57.3 \\
\hline & & & & $(\mathrm{p}=0.03)$ & & $(\mathrm{p}=0.01)$ \\
\hline \multirow[t]{3}{*}{ Profession } & $\begin{array}{c}\text { Executive/ } \\
\text { Non-executive }\end{array}$ & 320 & 158 & 49.4 & 177 & 55.3 \\
\hline & $\begin{array}{c}\text { Housewife/ } \\
\text { Unemployed }\end{array}$ & 236 & 110 & 46.6 & 123 & 52.1 \\
\hline & Student & & & & & \\
\hline
\end{tabular}

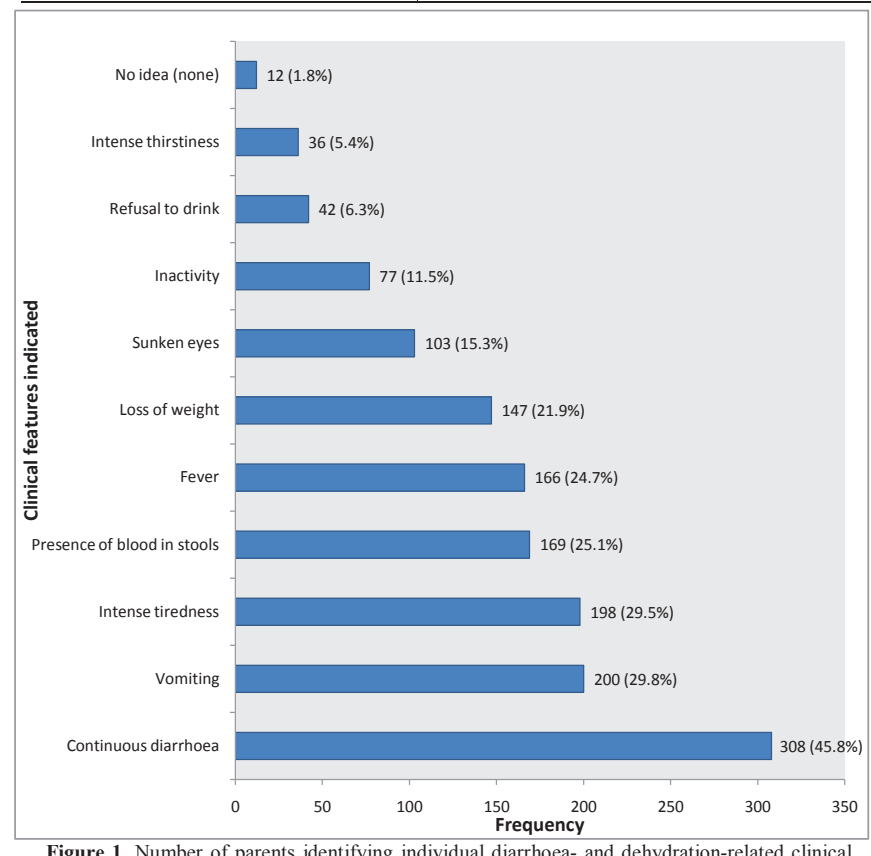

Figure 1. Number of parents identifying individual diarrhoea- and dehydration-related clinical features and danger sign

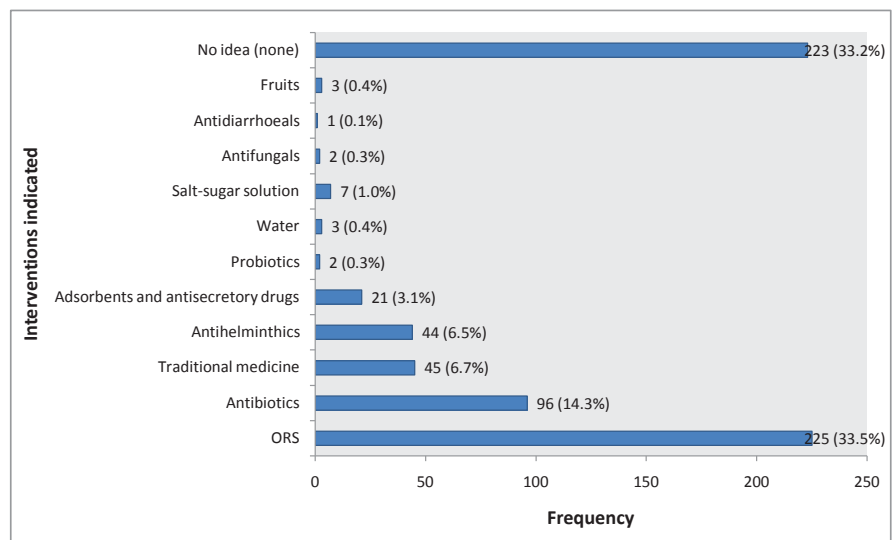

Figure 2. First choice of intervention by parents during a child's diarrhoeal episode

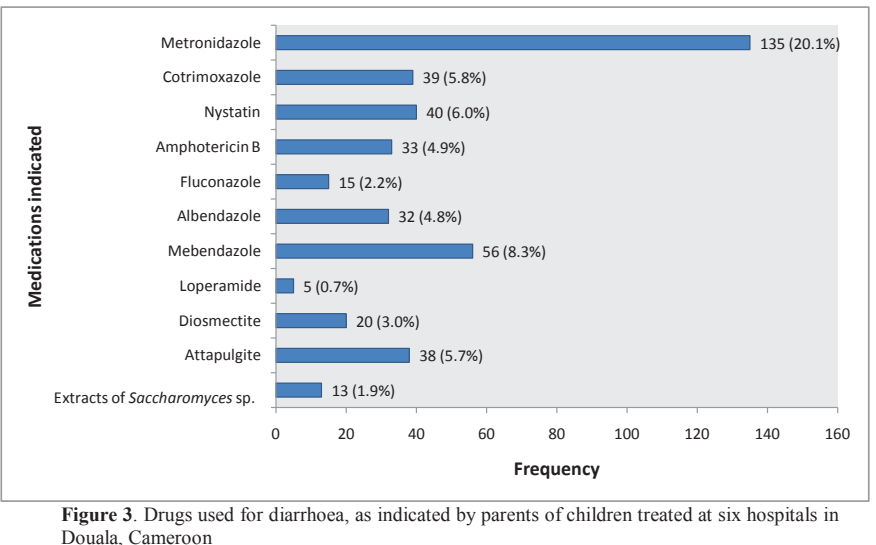

\section{Drugs used for diarrhoea}

Amongst the study participants, 135 (20.1\%) have given metronidazole to their children with diarrhoea. Fifty-six $(8.3 \%)$ have given their children mebendazole. Other drugs used are shown in Figure 3.

\section{Perception of the role of traditional medicine in diarrhoea}

One hundred nine parents $(16.2 \%)$ had used herbal remedies to treat their children's diarrhoea, among whom 45 gave it as first-line treatment. Among these 109 parents, 94 thought that it stopped diarrhoea, eight thought that it was used to destroy germs, and seven said it could prevent or reverse dehydration.

\section{Knowledge about ORS, SSS and sources of information}

Among the 672 parents, $90(13.4 \%)$ claimed to know about SSS, but only four of them knew its composition. Four hundred seventy five parents $(70.7 \%)$ had heard of ORS, and $114(17.0 \%)$ knew about the combined use of zinc tablets with ORS; 188 parents $(28.0 \%)$ had sachets of ORS at home. Information on ORS came mostly from the hospital, as reported by 258 parents $(54.3 \%)$. Relatives ( 84 responses, $17.7 \%)$, pharmacies $(73,15.4 \%)$, the media $(48,10.1 \%)$, and school $(12,2.5 \%)$ represented other sources of information for parents.

\section{Preparation, administration, and storage of ORS}

Among the 475 parents who had heard of ORS, 313 (65.9\%) had actually used it during their child's most recent diarrhoeal episode, and $217(45.7 \%)$ knew how to correctly prepare it. One hundred twenty-two parents $(25.7 \%)$ suggested that regular quantities of the solution should be consumed as part of treatment for diarrhoea. Three hundred seventeen $(66.7 \%)$ parents kept the mixed solution for at most 24 hours. Information on participant responses about preparation, administration and storage of ORS is shown in Table 2.

\section{Knowledge of the role of ORS by parents}

Two hundred thirty-four parents $(34.8 \%)$ thought that ORS is intended to prevent or treat dehydration. The other roles of ORS, according to parents, were to stop diarrhoea for 184 parents $(27.4 \%)$, provide energy (36 parents, $5.4 \%$ ), and to kill germs (17 parents, 2.5\%). Two hundred one parents $(29.9 \%)$ had no idea of the possible role of ORS.

\section{Factors influencing the use of ORT by parents}

The older a child, the more likely his or her parents reported use of ORS or SSS ( $p<0.05)$. A similar observation was made for the increase in the number of children in the family and the level of education of the parents — as the magnitudes 
of these variables increased, so did ORT use $(p=0.03$ and $\mathrm{p}=0.01$, respectively). The profession of the parents did not have a significant influence on the use of ORT $(p=0.1$, Table 3).

\section{Discussion}

\section{Socio-demographic data}

The study sample was made up of mostly women. In our socio-economic and cultural context, children are generally taken to medical consultations by their mothers. Parents of children aged one to twelve months were the most numerous because these parents consult regularly for healthcare services, but also for vaccination in the context of the expanded vaccination programme, covering the period from birth to eleven months of age. The predominant secondary level of education among participants is consistent with the national data, in which the majority of women $(65 \%)$ in Cameroon have an incomplete secondary level of education ${ }^{7}$. That the majority of the households had more than one child per home was in line with DHS-MICS 2011, which found that a household counts, on average, 4.3 people in Yaoundé and Douala ${ }^{7}$.

\section{Knowledge about diarrhoea and its severity}

The majority of the parents $(62.2 \%)$ were able to correctly define diarrhoea. Diarrhoea was quite well known to the parents because it is such a common disease. Parents were quite aware of the seriousness of this condition, but when analyzing the perceived signs as being signs of alarm, it was realized that they were more concerned by the manifestations of gastroenteritis itself (continuous diarrhoea and vomiting) than by serious signs of dehydration, such as thirst or refusal to drink and lethargy.

\section{The attitudes of parents towards a diarrhoeal episode}

A little more than half of parents (51.7\%) preferred referring their children to the hospital during bouts of diarrhoea. This was consistent with the observation that a large proportion of the participants $(33.1 \%)$ reported that they had no idea of what to do in the case of a diarrhoeal episode, but also with the perception of the potential seriousness of diarrhoea that $82.1 \%$ of the parents expressed. These data highlight the need for parent education on aspects of diarrhoea care that can be handled at home, so that children do not reach the hospital in a state of severe dehydration ${ }^{15}$.

A large proportion of the participants preferred to begin treatment at home from the onset of a child's diarrhoea. In Douala, an estimated $69.4 \%$ of households had resorted to medication not prescribed by a doctor for at least one patient in 20117. The most used drug for diarrhoea in children, as revealed in this study, was metronidazole, followed by mebendazole. A qualitative study on the management of diarrhoea in the Democratic Republic of Congo, conducted in 2008, also showed the frequent use of these two drugs in the treatment of diarrhoea in the Katanga, Kinshasa, and Kasai regions ${ }^{17}$. Most acute diarrhoeas of infants and young children have a viral origin and these treatments have no effect on these viruses ${ }^{18}$.

\section{Knowledge of ORT}

In this study 90 participants $(13.4 \%)$ had heard of SSS. This rate was lower than the $67.3 \%$ found in a study carried out in the Noun department ${ }^{12}$. The use of ORS in ready-made sachets has facilitated ORT use, and their availability and low cost have reduced the utilization of SSS, which demands the mixture of several ingredients that must be available and whose composition must be retained by the parents. Nevertheless, the number of parents with ORS available at home was $188(28.0 \%)$. It is important to explain the preparation of SSS to parents, because it could help in the rehydration of their children while waiting to obtain sachets of ORS. In 2011 the rate of awareness of the existence of ORS was $81.8 \%$, lower than that observed in 2004 (83.6\%). This study reveals a decrease to $70.6 \%$. This could be explained by the decline in awareness-raising campaigns ${ }^{7,19}$.

\section{The use, preparation, administration, and storage of ORS}

Less than half of the participants had actually used ORS during the most recent episodes of diarrhoea among their children, less than half of the participants knew how to prepare the ORS, and only a quarter knew how to administer it. Less than $35 \%$ of the participants were aware of the role of ORS. In contrast, the use of antibiotics, antifungals, antihelminthics and antidiarrhoeal drugs is widespread in diarrhoea ${ }^{20,21}$. Considering the morbidity and mortality from diarrhoea, it is important to readjust the messages transmitted to parents about diarrhoea and oral rehydration. It is necessary to strengthen parents' knowledge about diarrhoea and its treatment during hospital consultations, but also during health campaigns and through the media ${ }^{22,23}$.

\section{Conclusion}

In light of the results of this study, it is reasonable to say that the use of ORT by parents in the city of Douala is insufficient or poor. Advocacy efforts, with media engagement, must be provided by health authorities to parents, the community health facilities, and health workers in order to improve the use of ORT. The messages about diarrhoea and ORT should focus on the danger signs related to diarrhoea and dehydration, the preparation and administration of ORT, and its role in the treatment of childhood diarrhoea.

\section{Conflict of Interest:}

The authors report no conflicts of interest.

\section{Contribution of Authors}

NEE designed the study. All of the authors undertook the data collection, the statistical analysis and drafted the manuscript. All have approved the submitted version of the manuscript.

\section{References}

1. Bühler HF, Ignotti E, Neves SM, Hacon Sde S. Spatial analysis of integrated health and environmental indicators for morbidity and mortality due to infant diarrhea in Brazil, 2010. Cad Saude Publica. 2014 Sep;30(9):1921-34.

2. Mandomando IM, Macete EV, Ruiz J, Sanz S, Abacassamo F, Valles $\mathrm{X}$, et al. Etiology of diarrhoea in children younger than 5 years of age admitted in a rural hospital Southern Mozambique. Ame. J. Trop. Med. Hyg. 2007;76:522-527

3. Jegede EF, Oyeyi ET, Bichi AH, Mbah HA, Torpey K. Prevalence of intestinal parasites among HIV/AIDS patients attending Infectious Disease Hospital Kano, Nigeria. Pan Afr Med J. 2014 Apr 18;17:295.

4. Salim H, Karyana IP, Sanjaya-Putra IG, Budiarsa S, Soenarto Y. Risk factors of rotavirus diarrhea in hospitalized children in Sanglah Hospital, Denpasar: a prospective cohort study. BMC Gastroenterol. 2014 Mar 26;14:54. 
5. Fonds des Nations Unies pour l'Enfance. La survie et la santé des enfants dans le monde : un rapport d'UNICEF Canada sur les progrès réalisés en 50ans. UNICEF, Genève, 2006.

6. Organisation Mondiale de la Santé. Diarrhoea: Why children are still dying and what can be done. OMS, Genève, 2009.

7. Planification et de l'aménagement du territoire, Ministère de la santé publique [Cameroun]. Enquête démographique et de santé et à indicateurs multiples (EDS-MICS) 2011. Calverton, Maryland, USA : ICF International, Septembre 2012.

8. Santosham M, Chandran A, Fitzwater S, Fischer-Walker C, Baqui $\mathrm{AH}$, Black R, et al. Progress and barriers for the control of diarrhoeal disease. Lancet 2010;376:63-67

9. Olson CK, Blum LS, Patel KN, Oria PA, Feikin DR, Laserson KF, Wamae AW, Bartlett AV, Breiman RF, Ram PK. Community case management of childhood diarrhea in a setting with declining use of oral rehydration therapy: findings from cross-sectional studies among primary household caregivers, Kenya, 2007. Am J Trop Med Hyg. 2011 Dec;85(6):1134-40.

10. Chouraqui JP. Prise en charge diététique des diarrhées aiguës du nourrisson et du jeune enfant. Archives de Pédiatrie 2011;18:192-3

11. Organisation mondiale de la santé (OMS). Statistiques sanitaires mondiales 2011. Genève, OMS, 2011.

12. Van Der Geer ER, Prats J. La connaissance et l'utilisation de la réhydratation orale par les mères des enfants de 12 à 23 mois dans le département du Noun (Cameroun) en Mai 1988. Médecine d'Afrique noire 1992;39(4):261-7

13. Ministère de l'économie et des finances, Gouvernement du Cameroun, Fonds des Nations Unies pour l'Enfance (UNICEF). Rapport principal : Enquête à indicateurs multiples 2000 (MICS 2000). Cameroon 2000.

14. Institut National de la Statistiques. Annuaire statistiques du Cameroun 2010. Consulté le 03/12/2013. Disponible sur url : http:// www.statistics-cameroon.org/manager.php?id=6
15. B.Topuz. La mauvaise prise en charge de la diarrhée de l'enfant en France. Santé publique 2004/1;41: 27-35.

16. Shah SM, Ahmad A, Khalique N, Afzal S, Ansari AM, Khan Z. Home-based management of acute diarrhoeal disease in an urban slum of Aligarh, India. J Infect Dev Ctries 2012;6(2):137-42.

17. Schubert J, Diwete J. Étude qualitative sur la prise en charge de la diarrhée et l'introduction du Zinc en RDC (Katanga, Kasaï oriental, Kinshasa). République Démocratique du Congo : USAID ( United Nations AID) from the american people, BASICS, Mars 2008

18. Christa L Fischer Walker, Robert E Black. Zinc for the treatment of diarrhoea: effect on diarrhoea morbidity, mortality and incidence of future episodes Int. J. Epidemiol. (2010) 39 (suppl 1): i6doi: 10.1093/ ije/dyq023

19. Institut National de la Statistiques (INS). Enquête Démographique et de Santé, Cameroun 2004. Calverton, Maryland, USA Juin 2005.

20. Baqui AH, Black RE, El Arifeen S, Yunus M, Zaman K, Begum N, et al. Zinc therapy for diarrhoea increased the use of oral rehydration therapy and reduced the use of antibiotics in Bangladeshi children. Journal of Health Population and Nutrition 2004 Dec;22(4):440-2

21. Zwisler G, Simpson E, Moodley M. treatment of diarrhea in young children: results from surveys on the perception and use of oral rehydration solutions, antibiotics, and other therapies in India and Kenya. Journal of global health 2013;3(1):1-14

22. Levine AC, Munyaneza RM, Glavis-Bloom J, Redditt V, Cockrell HC, Kalimba B, Kabemba V, Musavuli J, Gakwerere M, Umurungi JP, Shah SP,Drobac PC. Prediction of severe disease in children with diarrhea in a resource-limited setting. PLoS One. 2013 Dec 3;8(12).

23. Sood N, Wagner Z. Private sector provision of oral rehydration therapy for child diarrhea in sub-Saharan Africa. Am J Trop Med Hyg. 2014 May;90(5):939-44. 